\title{
Measurement and evaluation of static characteristics of rotary hydraulic motor
}

\author{
Lumír Hružík $^{1, a}$, Martin Vašina ${ }^{1}$, and Adam Bureček ${ }^{1}$ \\ ${ }^{1}$ VŠB - Technical University of Ostrava, Faculty of Mechanical Engineering, Department of Hydromechanics and \\ Hydraulic Equipment, 70833 Ostrava, Czech Republic
}

\begin{abstract}
The paper describes experimental equipment for measurement of static characteristics of rotary hydraulic motor. It is possible to measure flow, pressure, temperature, speed and torque by means of this equipment. It deals with measurement of static characteristics of a gear rotary hydraulic motor. Mineral oil is used as hydraulic liquid in this case. Flow, torque and speed characteristics are evaluated from measured parameters. Measured mechanical-hydraulic, flow and total efficiencies of the rotary hydraulic motor are adduced in the paper. It is possible to diagnose technical conditions of the hydraulic motor (eventually to recommend its exchange) from the experimental measurements.
\end{abstract}

\section{Introduction}

Rotary hydraulic motors belong to hydrostatic converters that work on volumetric principle. The geometric volume $V_{g M}$ is one of their most important properties. The volume is given by a liquid volume, which flows through an unloaded hydraulic motor within one revolution of the motor shaft. A suitable rotary hydraulic motor is chosen on the basis of static characteristics. Flow, torque and speed characteristics belong to most important characteristics of hydraulic motors. The efficiency of rotary hydraulic motors is a very important parameter too. It is possible to diagnose e.g. technical conditions of rotary motors on the basis of their efficiency. In the case of hydraulic motors, it is necessary to determine flow, mechanical-hydraulic and total efficiencies. The abovementioned parameters of rotary motors are the basis for their suitable applications $[1,2]$.

\section{Description of experimental equipment}

The schematic diagram of the tested experimental equipment is shown in figure 1. The control hydraulic pump $\mathrm{HP}_{1}$ is a pressure liquid source and is used in order to drive the rotary hydraulic motor $\mathrm{HM}_{1}$. This motor is subsequently used to driving of the hydraulic pump $\mathrm{HP}_{2}$. The drive of the measured rotary hydraulic motor $\mathrm{HM}_{2}$ is realized in this manner. It is an internal-gear motor with the geometric volume $V_{g M 2}=8.16 \mathrm{~cm}^{3}$, which was experimentally verified (see chapter 3 ). The drive consists of the manometer $\mathrm{M}$ and the relief valve $\mathrm{RV}$, which is used to system overload protection. It is possible to adjust required flows by means of the control hydraulic pump $\mathrm{HP}_{1}$. The measured rotary hydraulic motor $\mathrm{HM}_{2}$ is loaded through the hydraulic pump $\mathrm{HP}_{3}$ and the pressure valve $\mathrm{PV}$. The gear flow sensor FS is connected to a line between the pump $\mathrm{HP}_{2}$ and the motor $\mathrm{HM}_{2}$. This sensor allows to measure flow (i.e. by the sensor $\mathrm{S}_{2}$ ), temperature (i.e. by the sensor $\mathrm{S}_{1}$ ) and pressure (i.e. by the sensor $S_{3}$ ). Speed (i.e. by the sensor $S_{5}$ ) and torque (i.e. by the sensor $\mathrm{S}_{4}$ ) are measured on shaft between the motor $\mathrm{HM}_{2}$ and the pump $\mathrm{HP}_{3}$. The pressure sensor $\mathrm{S}_{6}$ behind the motor $\mathrm{HM}_{2}$ makes it possible to measure the output pressure of the motor $\mathrm{HM}_{2}$. Mineral oil is used as working liquid in this case with the following parameters (at the temperature $t_{o}=25^{\circ} \mathrm{C}$ ): the density $\rho=870 \mathrm{~kg} \cdot \mathrm{m}^{-3}$ and the kinematic viscosity $v=80 \mathrm{~mm}^{2} \cdot \mathrm{s}^{-1}$. Measuring data were stored in memory of the measuring instrument M5050 [3]. The data were subsequently processed using Hydrowin software on personal computer (PC). Mean values of quantities were determined from their measured time dependencies. These measurements were performed during the time of $30 \mathrm{~s}$ with the scanning interval $\Delta t=100 \mathrm{~ms}$. All measurements were realized at the constant temperature of the working liquid. The temperature is measured by the temperature sensor $\mathrm{S}_{1}$ and hold by means of the cooler C [4].

\footnotetext{
a Corresponding author: lumir.hruzik@vsb.cz
} 


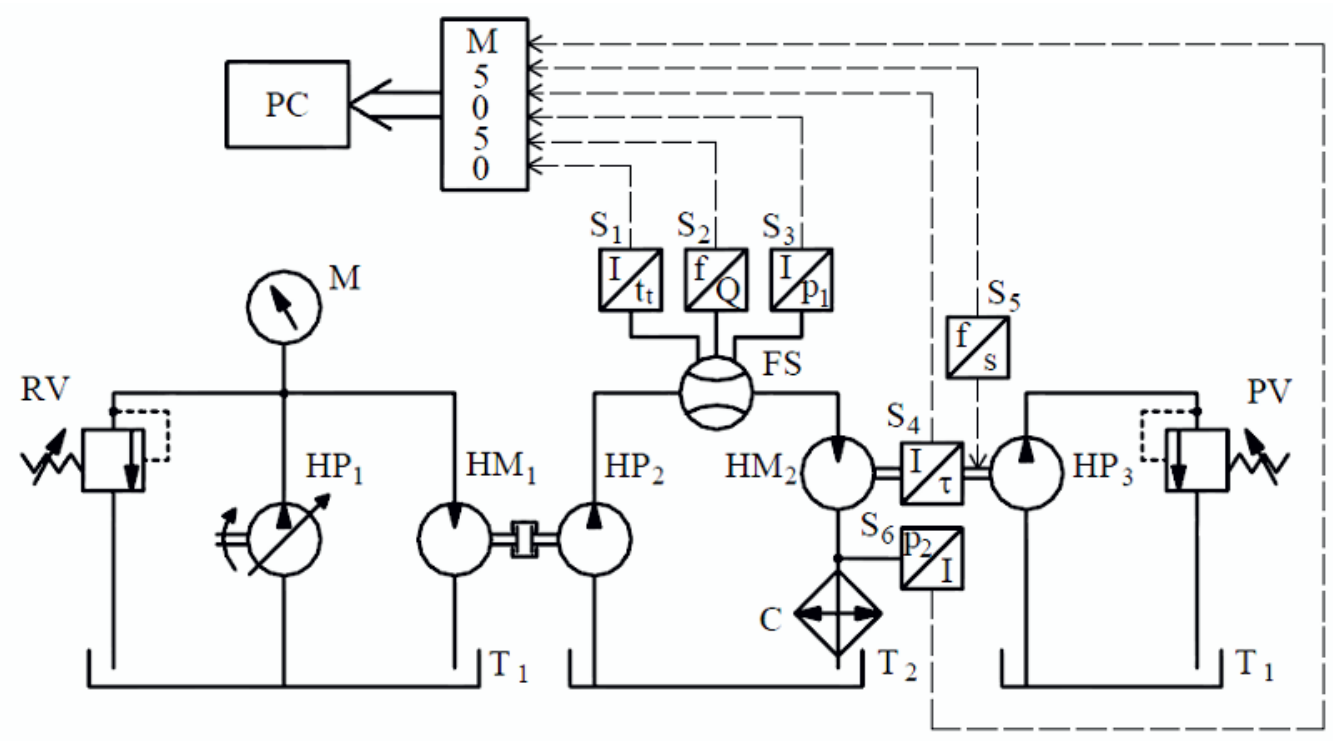

Figure 1. Schematic diagram of hydraulic system for experimental determination of static characteristics of rotary hydraulic motor.

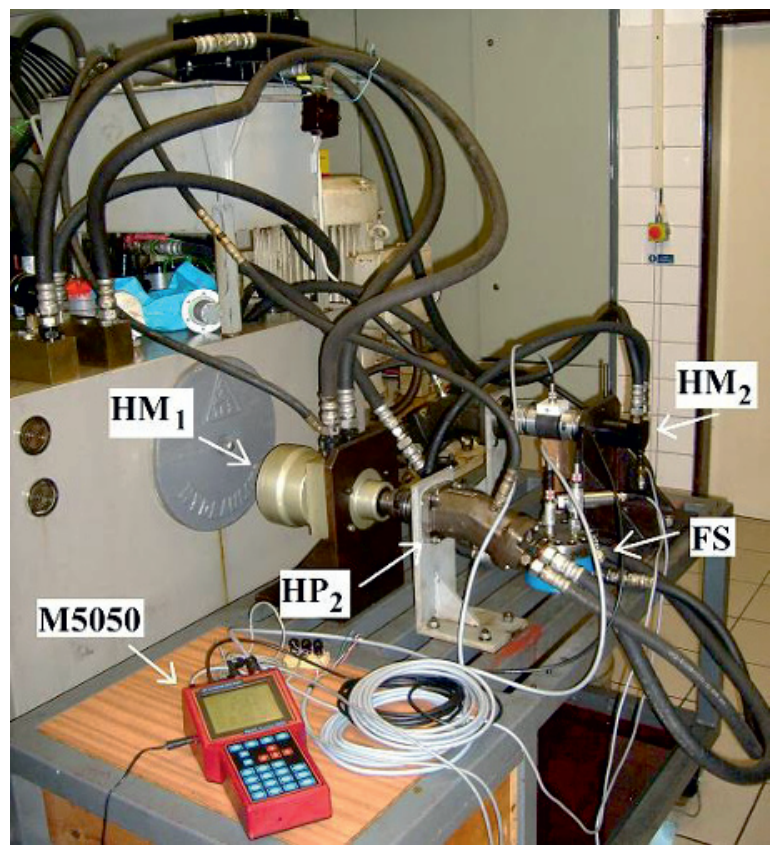

Figure 2. View of experimental equipment for determination of static characteristics of rotary hydraulic motor.

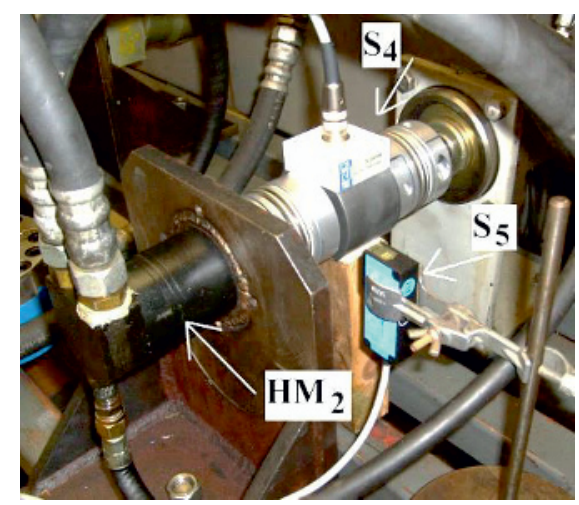

Figure 3. View of torque sensor $\mathrm{S}_{4}$ and speed sensor $\mathrm{S}_{5}$.
The legend of the used hydraulic elements (see figure 1) is the following:

$\mathrm{HP}_{1}$ - control hydraulic pump, $\mathrm{HP}_{2}, \mathrm{HP}_{3}$ - hydraulic pumps, $\mathrm{HM}_{1}, \mathrm{HM}_{2}$ - hydraulic motors, $\mathrm{RV}$ - relief valve, $\mathrm{PV}$ - pressure valve, FS - flow sensor, $\mathrm{T}_{1}, \mathrm{~T}_{2}-$ tanks, $\mathrm{C}$ cooler, $\mathrm{M}$ - manometer, $\mathrm{S}_{1}$ - temperature sensor, $\mathrm{S}_{2}-$ flow sensor, $\mathrm{S}_{3}, \mathrm{~S}_{6}$ - pressure sensors, $\mathrm{S}_{5}-$ speed sensor, $\mathrm{S}_{4}-$ torque sensor.

\section{Determination of geometric volume}

The geometric volume $V_{g M 2}$ of the hydraulic motor $\mathrm{HM}_{2}$ was experimentally determined in the following way: The flow characteristic of the motor $\mathrm{HM}_{2}$ depending on the speed $s_{M 2}$ (i.e. $Q_{M 2}=f\left(s_{M 2}\right)$ ) was measured for different values of the pressure gradient $\Delta p_{M 2}$. Its dependence is shown in figure 4.

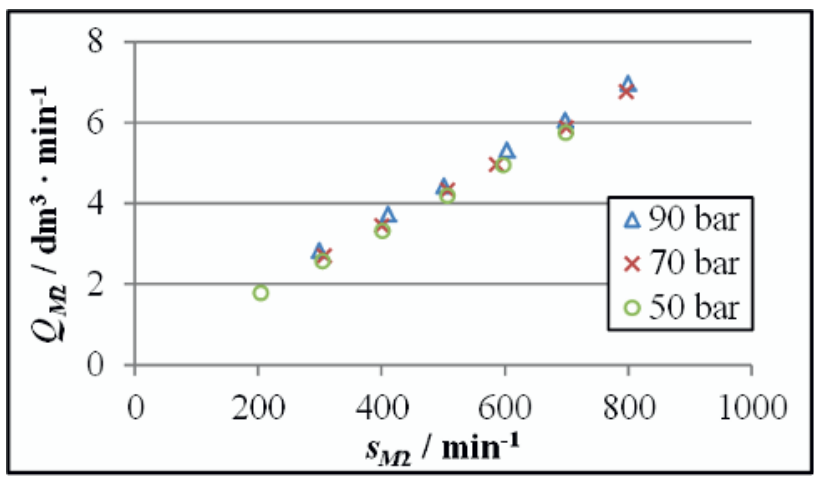

Figure 4. Verification of geometric volume of hydraulic motor from speed-flow characteristic.

With respect to the speed ratio $s_{M 2.2} / s_{M 2.1}=1.5 \div 3$, it is possible to determine the geometric volume of the motor from two values of the flows $Q_{M 2.1}$ and $Q_{M 2.2}$, which are proportional to the speeds $s_{M 2.1}$ and $s_{M 2.2}$ (see figure 5). The geometric volume is defined by the formula: 


$$
V_{g M 2}=\frac{\Delta Q}{\Delta s}=\frac{Q_{M 2.2}-Q_{M 2.1}}{s_{M 2.2}-s_{M 2.1}}
$$

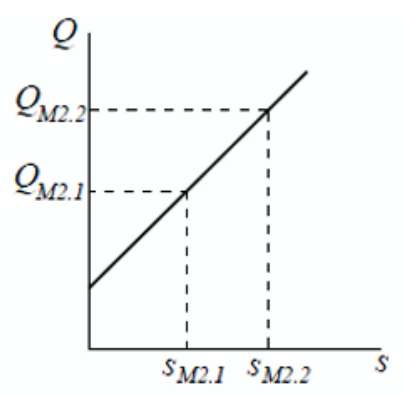

Figure 5. Course of flow $Q_{M 2}$ depending on speed $s_{M 2}$.

\section{Measurement methodologies of static characteristics}

\subsection{Flow characteristic}

The flow characteristic $Q_{M 2}=f\left(\Delta p_{M 2}\right)$ of the rotary hydraulic motor $\mathrm{HM}_{2}$ is given by the dependence of the input flow $Q_{M 2}$ into the motor on the pressure gradient $\Delta p_{M 2}$ through the motor at its constant speeds which are obtained by the control hydraulic pump $\mathrm{HP}_{1}$. The hydraulic motor $\mathrm{HM}_{2}$ is placed on shaft together with the torque sensor $\mathrm{S}_{4}$ and the hydraulic pump $\mathrm{HP}_{3}$ which is loaded by the pressure valve PV. For this reason, there is torque on the shaft between the pump $\mathrm{HP}_{3}$ and the motor $\mathrm{HM}_{2}$. The torque value is also proportional to the pressure gradient $\Delta p_{M 2}=p_{1}-p_{2}$ through the motor $\mathrm{HM}_{2}$. Speed measurements are performed by means of the optical frequency speed sensor $\mathrm{S}_{5}$. The flow is measured by the gear flow sensor FS (i.e. by the sensor $\mathrm{S}_{2}$ ). The input pressure $p_{1}$ and the output pressure $p_{2}$ of the motor $\mathrm{HM}_{2}$ are obtained by the pressure sensors $\mathrm{S}_{1}$ a $\mathrm{S}_{6}$. The example of the measured values at the speed $s_{M 2}=200 \mathrm{~min}^{-1}$ is adduced in table 1 [3].

Table. 1. Example of measured values for determination of flow characteristic at the speed $s_{M 2}=200 \mathrm{~min}^{-1}$.

\begin{tabular}{|c|c|c|c|c|c|c|}
\hline No. & $p_{1}$ & $p_{2}$ & $t_{o}$ & $Q_{M 2}$ & $s_{M 2}$ & $\Delta p_{M 2}$ \\
\hline$[-]$ & {$[\mathrm{bar}]$} & {$[\mathrm{bar}]$} & {$\left[{ }^{\circ} \mathrm{C}\right]$} & {$\left[\mathrm{dm}^{3} \cdot \mathrm{min}^{-1}\right]$} & {$\left[\mathrm{min}^{-1}\right]$} & {$[$ bar $]$} \\
\hline 1 & 35.3 & 0.3 & 24.8 & 1.66 & 201.8 & 35.0 \\
\hline 2 & 45.1 & 0.3 & 24.8 & 1.65 & 199.1 & 44.8 \\
\hline 3 & 56.4 & 0.3 & 24.9 & 1.73 & 204.3 & 56.1 \\
\hline 4 & 65.2 & 0.3 & 24.0 & 1.71 & 197.2 & 64.9 \\
\hline 5 & 76.5 & 0.3 & 24.0 & 1.78 & 200.8 & 76.2 \\
\hline 6 & 87.7 & 0.3 & 24.1 & 1.84 & 201.6 & 87.4 \\
\hline 7 & 96.3 & 0.3 & 24.2 & 1.87 & 199.4 & 96.0 \\
\hline 8 & 108.5 & 0.3 & 24.3 & 1.90 & 191.9 & 108.2 \\
\hline
\end{tabular}

\subsection{Torque characteristic}

The torque characteristic $\tau_{M 2}=f\left(s_{M 2}\right)$ is defined by the dependence of the torque $\tau_{M 2}$ on the shaft of the hydraulic motor $\mathrm{HM}_{2}$ on the speed $s_{M 2}$ at the pressure gradient $\Delta p$ through the motor $\mathrm{HM}_{2}$. The speed $s_{M 2}$ is regulated by the control hydraulic pump $\mathrm{HP}_{1}$. The required pressure gradient $\Delta p_{M 2}$ is obtained by the pressure valve PV. The pressure gradient and the speed are measured in a similar manner as in the case of the above-mentioned flow characteristic measurement. The torque measurements are performed by means of the torque sensor $\mathrm{S}_{4}$ that is placed on the shaft between the motor $\mathrm{HM}_{2}$ and the pump $\mathrm{HP}_{3}$. The example of the measured values for the pressure gradient $\Delta p=50$ bar is adduced in table 2 .

Table 2. Example of measured values for determination of torque characteristic for the pressure gradient $\Delta p=50$ bar.

\begin{tabular}{|c|c|c|c|c|c|c|c|}
\hline No. & $p_{1}$ & $p_{2}$ & $t_{o}$ & $Q_{M 2}$ & $s_{M 2}$ & $\tau_{M 2}$ & $\Delta p_{M 2}$ \\
\hline$[-]$ & {$[\mathrm{bar}]$} & {$[\mathrm{bar}]$} & {$\left[{ }^{\circ} \mathrm{C}\right]$} & {$\left[\mathrm{dm}^{3} \cdot \mathrm{min}^{-1}\right]$} & {$\left[\mathrm{min}^{-1}\right]$} & {$[\mathrm{N} \cdot \mathrm{m}]$} & {$[\mathrm{bar}]$} \\
\hline 1 & 51.0 & 0.2 & 25.3 & 1.77 & 204.9 & 4.72 & 50.8 \\
\hline 2 & 50.8 & 0.3 & 25.3 & 2.56 & 304.7 & 4.51 & 50.5 \\
\hline 3 & 50.0 & 0.3 & 25.3 & 3.31 & 401.9 & 4.19 & 49.7 \\
\hline 4 & 50.4 & 0.4 & 25.4 & 4.18 & 507.2 & 4.03 & 50.0 \\
\hline 5 & 49.9 & 0.5 & 25.5 & 4.94 & 598.1 & 3.81 & 49.4 \\
\hline 6 & 51.0 & 0.6 & 25.5 & 5.74 & 699.4 & 3.65 & 50.4 \\
\hline
\end{tabular}

\subsection{Speed characteristic}

The speed characteristic $s_{M 2}=f\left(\tau_{M 2}\right)$ is given by the dependence of the speed $s_{M 2}$ on the torque $\tau_{M 2}$ of the motor $\mathrm{HM}_{2}$ at the volume flow $Q_{M 2}$ into the motor $\mathrm{HM}_{2}$. In this case, the torque on the shaft of the motor $\mathrm{HM}_{2}$ is controlled by means of the pressure valve PV. The input flow $Q_{M 2}$ into the motor HM2 is maintained constant by the control pump $\mathrm{HP}_{1}$. The example of the measured values for the flow $Q_{M 2}=2 \mathrm{dm}^{3} \cdot \mathrm{min}^{-1}$ is adduced in table 3 .

Table 3. Example of measured values for determination of speed characteristic at the volume flow $Q_{M 2}=2 \mathrm{dm}^{3} \cdot \mathrm{min}^{-1}$.

\begin{tabular}{|c|c|c|c|c|c|c|c|}
\hline No. & $p_{1}$ & $p_{2}$ & $t_{o}$ & $Q_{M 2}$ & $s_{M 2}$ & $\tau_{M 2}$ & $\Delta p_{M 2}$ \\
\hline$[-]$ & {$[\mathrm{bar}]$} & {$[\mathrm{bar}]$} & {$\left[{ }^{\circ} \mathrm{C}\right]$} & {$\left[\mathrm{dm}^{3} \cdot \mathrm{min}^{-1}\right]$} & {$\left[\mathrm{min}^{-1}\right]$} & {$[\mathrm{N} \cdot \mathrm{m}]$} & {$[\mathrm{bar}]$} \\
\hline 1 & 32.9 & 0.2 & 25.1 & 2.04 & 240.5 & 2.79 & 32.7 \\
\hline 2 & 39.7 & 0.2 & 25.1 & 2.02 & 239.2 & 3.54 & 39.5 \\
\hline 3 & 49.2 & 0.2 & 25.2 & 2.04 & 238.0 & 4.62 & 49.0 \\
\hline 4 & 59.7 & 0.2 & 25.3 & 2.04 & 230.9 & 5.85 & 59.5 \\
\hline 5 & 68.9 & 0.2 & 25.3 & 2.03 & 224.3 & 6.92 & 68.7 \\
\hline 6 & 77.4 & 0.2 & 25.4 & 2.01 & 214.2 & 7.91 & 77.2 \\
\hline
\end{tabular}

\section{Evaluation of flow, torque and speed characteristics}

\subsection{Flow characteristic}

The flow characteristics $Q_{M 2}=f\left(\Delta p_{M 2}\right)$ of the rotary hydraulic motor $\mathrm{HM}_{2}$ for different values of the speed $s_{M 2}$ (i.e. $200 \mathrm{~min}^{-1}, 400 \mathrm{~min}^{-1}, 600 \mathrm{~min}^{-1}$ and $800 \mathrm{~min}^{-1}$ ) are 
shown in figure 6 . It is evident that it is necessary to increase the flow $Q_{M 2}$ on the input into the motor $\mathrm{HM}_{2}$ at increasing the pressure gradient $\Delta p_{M 2}$ through the motor $\mathrm{HM}_{2}$ in order to maintain the constant speed $s_{M 2}[5]$.

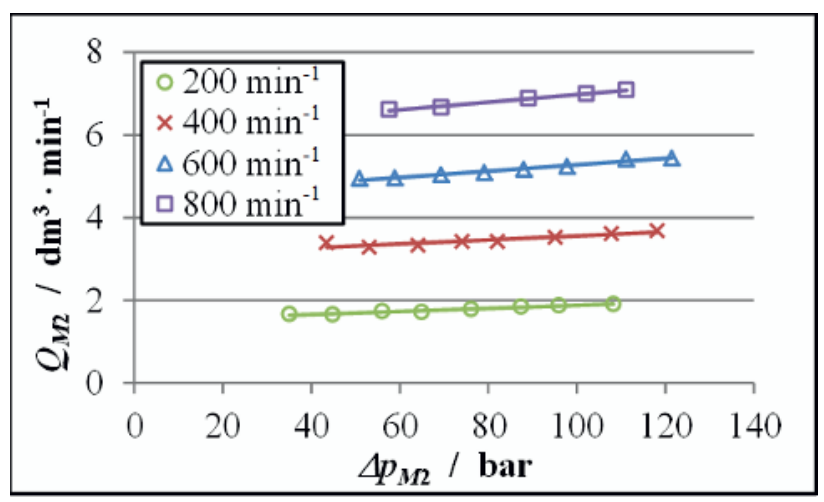

Figure 6. Flow characteristics of hydraulic motor $\mathrm{HM}_{2}$ at different speeds $s_{M 2}$ and the oil temperature $t_{o}=25^{\circ} \mathrm{C}$.

\subsection{Torque characteristic}

The torque characteristics $\tau_{M 2}=f\left(s_{M 2}\right)$ of the rotary hydraulic motor $\mathrm{HM}_{2}$ for different values of the pressure gradient $\Delta p_{M 2}$ (i.e. 50 bar, 70 bar and 90 bar) are demonstrated in figure 7 . It can be concluded at the given pressure gradients, that the motor torque on its shaft is decreasing with increasing the motor speed [5].

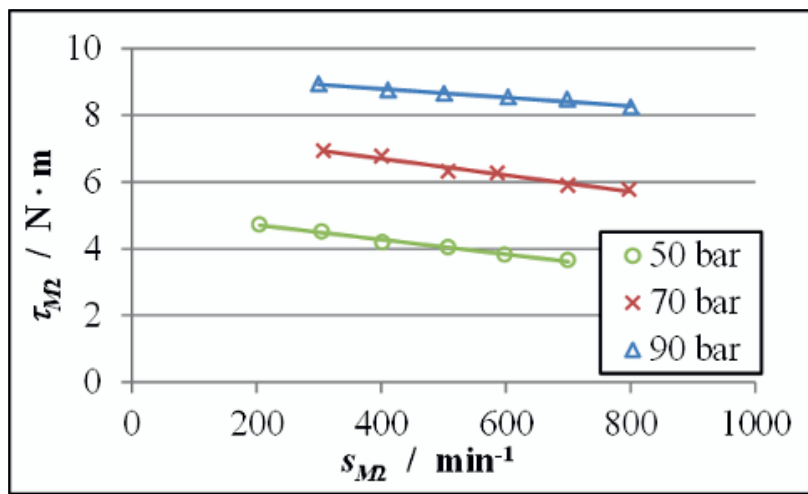

Figure 7. Torque characteristics of hydraulic motor $\mathrm{HM}_{2}$ for different pressure gradients $\Delta p_{M 2}$ and the oil temperature $t_{o}=25^{\circ} \mathrm{C}$.

\subsection{Speed characteristic}

The speed characteristics $s_{M 2}=f\left(\tau_{M 2}\right)$ of the rotary hydraulic motor $\mathrm{HM}_{2}$ for different values of the volume flow $Q_{M 2}$ (i.e. $2 \mathrm{dm}^{3} \cdot \mathrm{min}^{-1}, 4 \mathrm{dm}^{3} \cdot \min ^{-1}$ and $6 \mathrm{dm}^{3} \cdot \mathrm{min}^{-1}$ ) are shown in figure 8 . It is evident that the speed $s_{M 2}$ is decreasing with increasing the motor torque $\tau_{M 2}$ (see figure 8) [5].

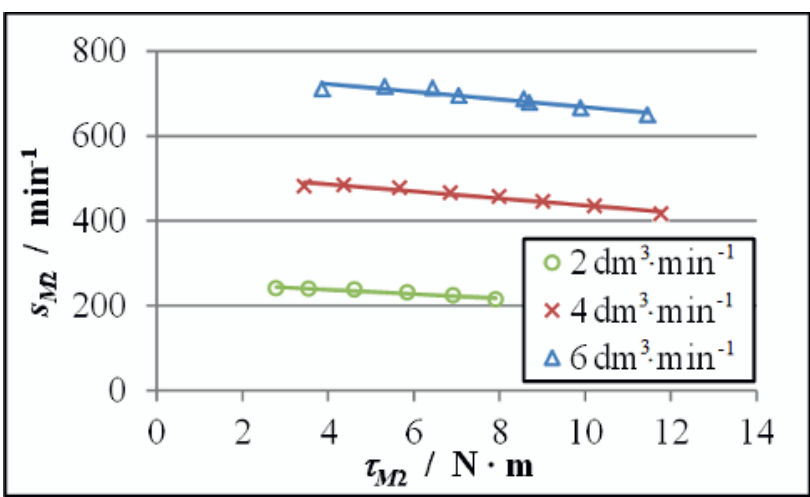

Figure 8. Speed characteristics of hydraulic motor $\mathrm{HM}_{2}$ for different volume flows $Q_{M 2}$ and the oil temperature $t_{o}=25^{\circ} \mathrm{C}$.

\section{Determination of flow, mechanical- hydraulic and total efficiency of rotary hydraulic motor}

\subsection{Flow efficiency}

The flow efficiency $\eta_{Q M 2}$ of the investigated rotary hydraulic motor $\mathrm{HM}_{2}$ is expressed by the equation:

$$
\eta_{Q M 2}=\frac{V_{g M 2} \cdot s_{M 2}}{Q_{M 2}}
$$

The flow efficiency is strongly influenced by viscosity of used liquid. Mineral oil with the kinematic viscosity $v=80 \mathrm{~mm}^{2} \cdot \mathrm{s}^{-1}$ at the temperature $t_{o}=25^{\circ} \mathrm{C}$ was used as the working liquid. The liquid viscosity and the flow efficiency are in general decreasing with increasing the liquid temperature.

The flow efficiencies depending on the pressure gradient $\Delta p_{M 2}$ of the rotary hydraulic motor $\mathrm{HM}_{2}$ for different values of the speed $s_{M 2}$ (i.e. $200 \mathrm{~min}^{-1}$, $400 \mathrm{~min}^{-1}, 600 \mathrm{~min}^{-1}$ and $800 \mathrm{~min}^{-1}$ ) are shown in figure 9. It is visible that the flow efficiency is decreasing with increasing the pressure gradient $\Delta p_{M 2}$ of the motor. Furthermore, the flow efficiency is increasing with increasing the motor speed [2].

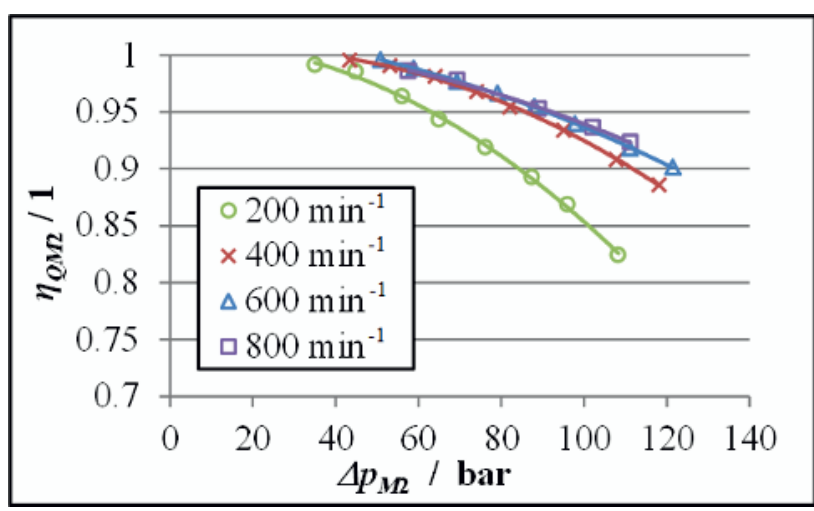

Figure 9. Flow efficiencies depending on pressure gradient $\Delta p_{M 2}$ of rotary hydraulic motor $\mathrm{HM}_{2}$ at different speeds $s_{M 2}$ and the oil temperature $t_{o}=25^{\circ} \mathrm{C}$. 


\subsection{Mechanical-hydraulic efficiency}

Mechanical-hydraulic efficiency $\eta_{m h M 2}$ is defined by the formula:

$$
\eta_{m h M 2}=\frac{2 \cdot \pi \cdot \tau_{M 2}}{\Delta p_{M 2} \cdot V_{g M 2}}
$$

The mechanical-hydraulic efficiencies depending on the pressure gradient $\Delta p_{M 2}$ of the rotary hydraulic motor $\mathrm{HM}_{2}$ for different values of the speed $s_{M 2}$ (i.e. $200 \mathrm{~min}^{-1}$, $400 \mathrm{~min}^{-1}, 600 \mathrm{~min}^{-1}$ and $800 \mathrm{~min}^{-1}$ ) are shown in figure 10. It was found that the mechanical-hydraulic efficiency is increasing with increasing the pressure gradient $\Delta p_{M 2}$. On the contrary, the efficiency is decreasing with increasing the speed [2].

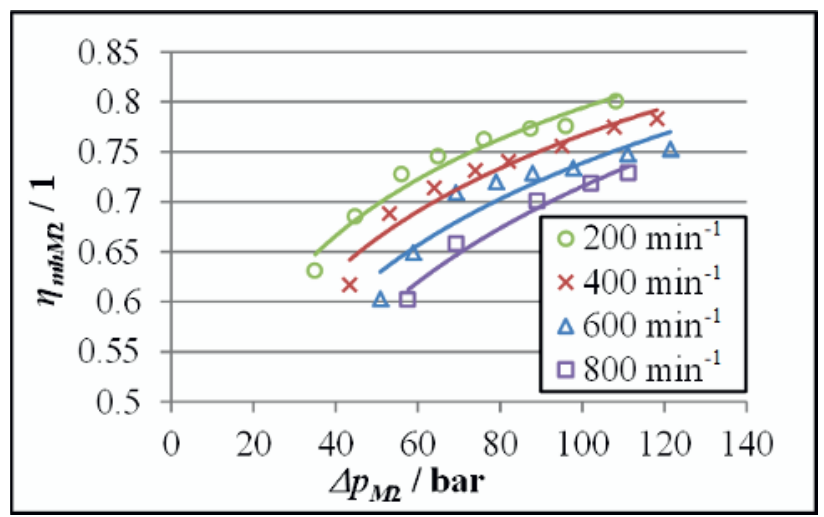

Figure 10. Mechanical-hydraulic efficiencies depending on pressure gradient $\Delta p_{M 2}$ of rotary hydraulic motor $\mathrm{HM}_{2}$ at different speeds $s_{M 2}$ and the oil temperature $t_{o}=25^{\circ} \mathrm{C}$.

\subsection{Total efficiency}

The total efficiency $\eta_{c M 2}$ is given by the product of the flow efficiency and the mechanical-hydraulic efficiency:

$$
\eta_{C M 2}=\eta_{Q M 2} \cdot \eta_{m h M 2}
$$

The total efficiencies depending on the pressure gradient $\Delta p_{M 2}$ of the rotary hydraulic motor $\mathrm{HM}_{2}$ for different values of the speed $s_{M 2}$ (i.e. $200 \mathrm{~min}^{-1}$, $400 \mathrm{~min}^{-1}, 600 \mathrm{~min}^{-1}$ and $800 \mathrm{~min}^{-1}$ ) are shown in figure 11 .

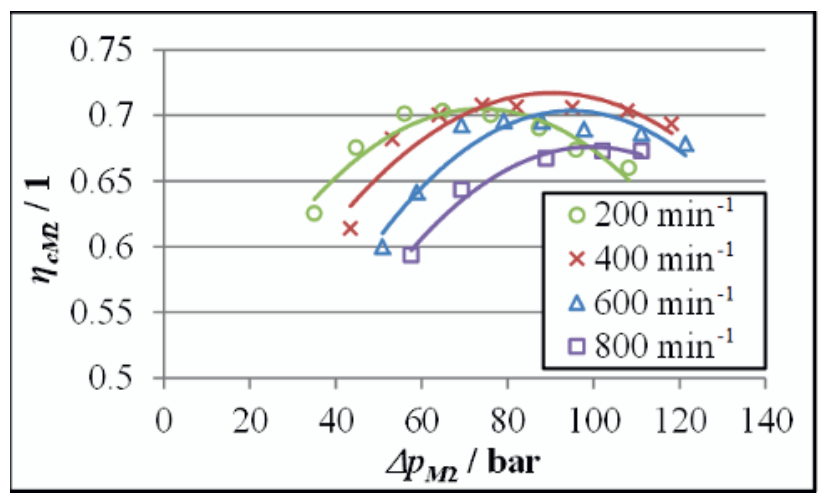

Figure 11. Total efficiencies depending on pressure gradient $\Delta p_{M 2}$ of rotary hydraulic motor $\mathrm{HM}_{2}$ at different speeds $s_{M 2}$ and the oil temperature $t_{o}=25^{\circ} \mathrm{C}$.

\section{Conclusions}

There is described the experimental hydraulic system for determination of static characteristics of rotary hydraulic motors in this article. Technical parameters of the investigated system are the following: $p_{\max }=160 \mathrm{bar}$, $Q_{\max }=25 \mathrm{dm} \mathrm{dm}^{3} \cdot \mathrm{min}^{-1}, \tau_{\max }=40 \mathrm{~N} \cdot \mathrm{m}$. The system makes it possible to measure static characteristics of rotary hydraulic motors for different working liquids at required temperatures. The flow, torque and speed characteristics were measured by this equipment. The efficiencies are strongly influenced by speed, pressure gradient and working liquid. The geometric volume of the rotary hydraulic motor was experimentally measured too. The flow, mechanical-hydraulic and total efficiencies were obtained from the measured values. The efficiencies depend on pressure gradient and speed too. For the given hydraulic motor $\mathrm{HM}_{2}$, the pressure gradient $\Delta p_{M 2}=90 \mathrm{bar}$ and the speed $s_{M 2}=600 \mathrm{~min}^{-1}$, the measured values of the efficiencies are the following: $\eta_{Q M 2}=0.95, \eta_{m h M 2}=0.73$ and $\eta_{c M 2}=0.695$. It is possible to obtain further values of the efficiencies from the measured graphic dependencies.

\section{References}

1. J. Kopáček, Technická diagnostika hydraulických mechanizmu (SNTL, Praha, 1990)

2. Z. Paszota, Energy Losses in the Hydraulic Rotational Motor Definitions and Relations for Evaluation of the Efficiency of Motor and Hydrostatic Drive, 17, 10 (Polish Maritime Research 2(65), 2010)

3. Hydrotechnik $\mathrm{GmbH}$, (catalog sheets)

4. L. Hružík, Průtoková účinnost hydromotoru s emulzí, Aplikovaná mechanika (Ostrava, 2002)

5. D. Will, T. Gebhardt, Hydraulic Grundlagen, Komponenten, Schaltungen (Springer, Berlin, 2008)

\section{Acknowledgements}

This paper has been elaborated in the framework of the project Opportunity for young researchers, reg. no. CZ.1.07/2.3.00/30.0016, supported by Operational Programme Education for Competitiveness and cofinanced by the European Social Fund and the state budget of the Czech Republic. 